\title{
Understanding and improving community flood preparedness and response: a research framework
}

Peer Reviewed

\section{Neil Dufty ${ }^{1}$}

1 Molino Stewart Pty Ltd, Sydney, New South Wales.

\section{SUBMITTED}

16 September 2020

\section{ACCEPTED}

8 October 2020

DOI

www.doi.org/10.47389/36.2.19

\section{(c) 1 (1) (9)}

(c) 2021 by the authors. License Australian Institute for Disaster Resilience Melbourne, Australia. This is an open access article distributed under the terms and conditions of the Creative Commons Attribution (CC BY) license (https:// creativecommons.org/ icenses/by/4.0/1)

\section{Introduction}

There has been a large volume of research conducted to understand why people and communities prepare and respond to hazard events in the way they do. Much of this research is guided by psychological theories and models including the Protection Motivation Theory, the Protective Action Decision Model and several socio-cognitive models. Grothmann and Reusswig (2006) introduced the Protection Motivation Theory, originally developed in health psychology, to flood-risk research. The theory suggests that the motivation to protect from a specific threat depends on how a person balances threat appraisal against coping appraisal (Rogers 1983). Subsequently, an increasing number of studies have applied the Protection Motivation Theory as a theoretical framework to explain protective behaviour of citizens at risk from a range of hazards.

A theoretical model that helps understand the process of decision-making in response to imminent threats is the Protective Action Decision Model produced by Lindell and Perry (2004). The model can be used for all phases of the disaster management cycle including preparedness and response. It proposes that people work through a series of pre-decisional and decision-making stages. According to the Protective Action Decision Model, the process of protective action decision-making begins with environmental cues (e.g. the sight or sound of a hazard such as floodwaters), social cues (observations of other's behaviour) and warnings (official advice to evacuate). These trigger a series of pre-decisional processes that stimulate the receiver to consider their perception of the threat, alternative options for protective action and their perceptions of the relevant stakeholders involved.

An example of a socio-cognitive model is that primarily developed by Paton, Mclvor and Johnston (Mclvor et al. 2009). It is a theoretical model designed to understand people's disaster preparedness. The model proposes that people's beliefs regarding the effectiveness of hazard preparedness interact with social-context factors (community participation, collective efficacy, empowerment and trust) to influence levels of hazard preparedness.

\section{Abstract}

Many social research projects identify issues with community disaster preparedness and response but struggle to attribute these issues to underlying causes and recommend possible ways to address them. A research framework that considers the underlying causes of preparedness and response and possible

interventions was developed for the Wimmera region of Victoria, Australia. The research framework was developed in conjunction with the Wimmera Catchment Management Authority and tested in a social research project across 6 communities in the Wimmera region. This paper provides an outline and rationale for the components of the research framework. It also summarises the regional flood insight afforded by the research framework. The research framework, albeit with some limitations, has universal appeal not only in the examination of community flood preparedness and response, but also for other hazards and other parts of the disaster management cycle. 
There has also been extensive social research into the state of disaster preparedness and response using a series of indicators. For example, for several years Healthcare Ready in the USA has conducted surveys into levels of resident disaster preparedness (Healthcare Ready 2020). Furthermore, interventions to improve disaster preparedness and response levels (e.g. community disaster education and engagement, early warning systems, communications, emergency management planning) have been heavily researched. For example, the New Zealand Government monitored for several years the effectiveness of its 'Get Ready Get Thru' social marketing education campaign (New Zealand Ministry of Civil Defence \& Emergency Management 2013). However, there has been relatively scant research that has probed the complexities associated with the nexus between the psychological and sociological contributing factors of disaster preparedness and response, community preparedness and response levels, and interventions that can influence those levels.

This complex relationship was examined during 2020 in a flood project commissioned by the Wimmera Catchment Management Authority (Wimmera CMA) in the Wimmera region of western Victoria, Australia. The success of the 2017 Wimmera Floodplain Management Strategy (Wimmera CMA 2017) is largely dependent on preparedness and response to flooding in the region. Regardless of the mitigation structures (e.g. levees) and nonstructural mitigation methods (e.g. property modifications, landuse planning), there will always be some residual risk for communities and emergency agencies to deal with in floods up to the probable maximum flood. Therefore, an understanding of the reaction to residual flood risk, initially via community preparedness and response (and then recovery), is central to the overall effectiveness of the strategy and the Wimmera region's flood resilience.

This paper outlines the research framework used to help understand and improve community flood preparedness and response in the Wimmera region. It also summarises the regional flood insight afforded by the research framework.

\section{Methodology}

A research framework (Figure 1) was initially constructed following a workshop with Wimmera CMA. It draws on the findings of relevant research related to the 2017 Wimmera Floodplain Management Strategy in 3 areas:

1. Contributing factors - the main psychological, sociological and demographic features potentially influencing community flood preparedness and response in the Wimmera region.

2. Preparedness and response levels - the common indicators used to measure these levels.

3. Interventions - the measures used to attempt to influence preparedness and response levels.

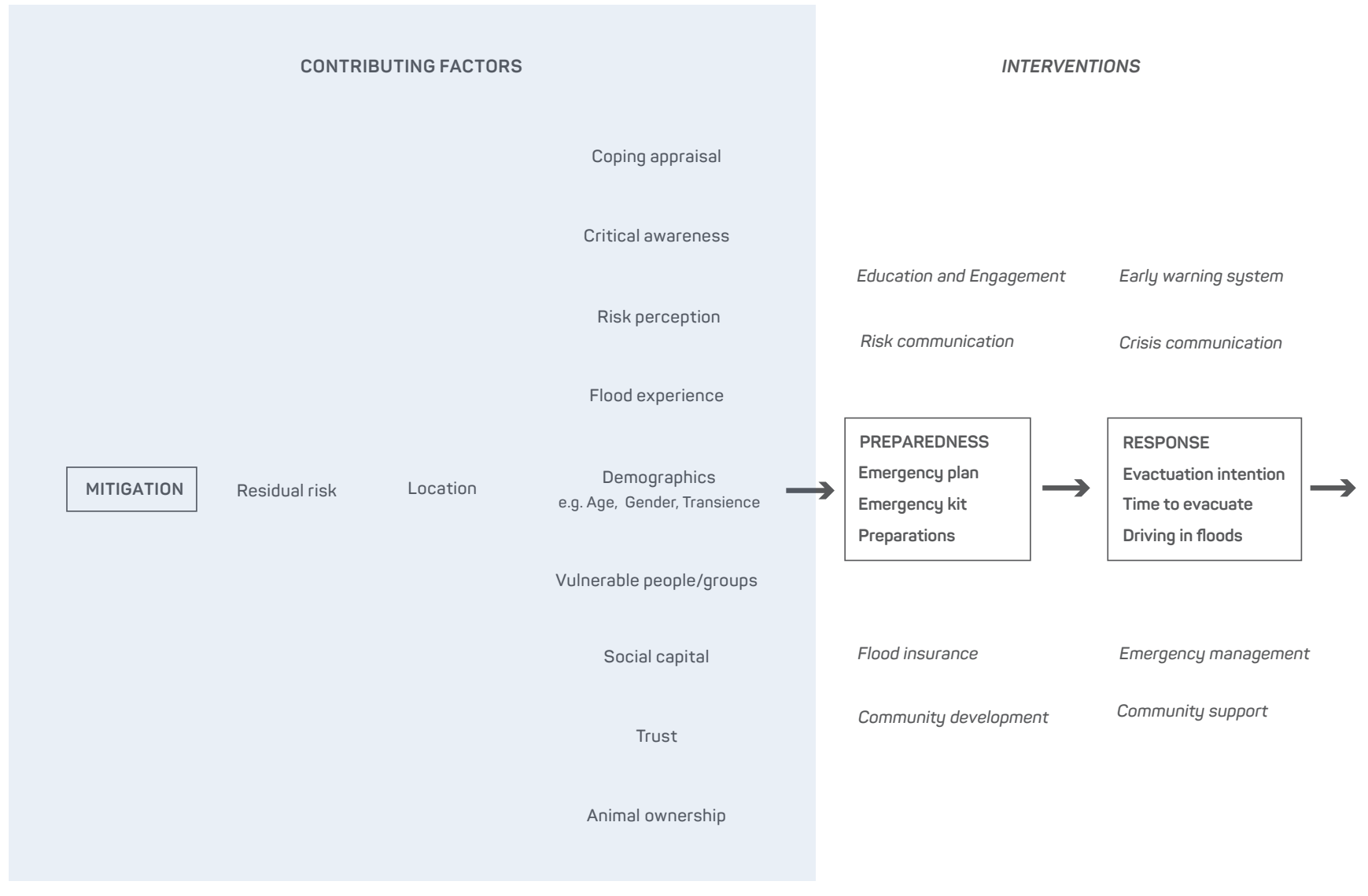

Figure 1: Research framework designed to examine community flood preparedness and response. 
The research framework was used in a social research project in 6 communities in the Wimmera region. A survey of the communities related to the research framework was developed and distributed to randomly selected residences across 5 flood categories representing total flood risk and considering a full range of possible flooding based upon flood studies in the region identified by Wimmera CMA.

The social research was conducted in line with the principles in the National Statement on Ethical Conduct in Human Research (National Health and Medical Research Council 2015).

\section{Results}

\section{Contributing factors}

The contributing factors identified for the research framework were:

- Coping appraisal - is a contributing factor identified in several of the psychological theories and models and was included in the research framework. Coping appraisal refers to the cognitive process by which a person evaluates possible responses that may reduce the perceived threat.

- Critical awareness - people will not prepare for floods and other hazards if they are unaware of the risks. However, extensive research shows that simply being aware of risks is not a strong factor for the initiation of responsible adaptive behaviours such as preparedness and safe response decisions (Karanci et al. 2005). Nonetheless, critical awareness has been shown to be a motivator of preparedness behaviours (Paton et al. 2006). According to Paton and co-authors (2006), 'critical awareness is the extent to which people perceive hazard issues as important enough to think about them and to discuss them on a regular basis'.

- Risk perception - there is ambivalence in the research regarding the role of risk perception in influencing preparedness and appropriate response behaviours. Some research has found a strong correlation between risk perception and flood preparedness and response actions (Terpstra et al. 2009, Miceli et al. 2008) while others have not (Bubeck et al. 2012, Scolobig et al. 2012). Nevertheless, it was decided to include risk perception in the research framework due to observations by local floodplain managers and emergency managers that this could be an important contributing factor in the Wimmera region.

- Flood experience - a long-standing hypothesis is that previous experience with an emergency or disaster will make an individual more likely to perform protective behaviours. Whether people prepare or not appears to depend on the severity of their experience and how that experience has been interpreted (Becker et al. 2017). With the last big flood event in the Wimmera region occurring in 2011 (approximately 1\% Annual Exceedance Probability flood), it was important to examine the influence of flood experience on current preparedness and potential response behaviours.

- Location and demographics - 6 towns in the Wimmera region of varying size and residual flood risk were identified for the research. Three demographic features of these populations (age, transience and gender) were identified for testing using the research framework.

- Vulnerable people and groups - there are numerous definitions of 'social vulnerability' (van der Veen et al. 2009). One well-supported definition of social vulnerability is 'the susceptibility of social groups to potential losses from hazard events or society's resistance and resilience to hazard' (Blaikie et al. 1994). A natural or technological hazard can have different short- or long-term impacts on various groups within society (Bankoff et al. 2004). A person's gender, age, physical abilities, ethnicity and sexuality, for instance, can lead to a higher risk of death or injury, longer recovery times or greater risk of mental or physical trauma.

- Social capital - the body of sociological evidence demonstrates the importance of connected communities across the disaster management cycle including preparedness and response (Aldrich 2012). Social capital has been defined as the 'networks, norms, and social trust that facilitate coordination and cooperation for mutual benefit' (Putnam 1995). It consists of those bonds created by belonging to a group that instils trust, solidarity and cooperation among members.

- Trust is a subset of social capital - this includes trust in authorities (e.g. in communication of flood warnings and risk communication). It becomes even more important when the individual's knowledge about the hazard is low and they depend on authorities for risk information (Cope et al. 2010).

- Animal ownership - this is a contributing factor to preparedness and response, particularly in rural areas such as the Wimmera region where residents may own both companion animals (pets) and livestock. Animal owners may risk their lives to save their animals (Thompson 2013). Many animal owners report high levels of attachment to their animals, often considering them to be part of the family. According to Thompson (2018), 'many guardians experience similar types and levels of attachment to their companion animals as those they may also experience towards the human members of their family - partners, children, parents and siblings'.

It should be noted that these contributing factors may be intertwined. For example, risk perception of residents can be strongly influenced by flood experience and social capital.

\section{Preparedness and response indicators}

There are numerous indicators that could be used to measure community preparedness and response levels (Healthcare Ready 2020). For assessing community preparedness levels in the Wimmera region (see Figure 1), 3 indicators were chosen:

1. Emergency plan. Emergency services organisations such as the Victoria State Emergency Service (VICSES) and the Country Fire Authority encourage people and businesses in the Wimmera region to have written emergency plans for hazard risks such as floods and bushfires. The development of written household and business flood emergency plans should be part of preparedness actions. 
2. Emergency kit. Emergency services organisations encourage Wimmera householders to have emergency kits. Suggested items for these kits include a first aid kit, candles, waterproof matches and non-perishable food for 72 hours.

3. Preparations. There is a range of actions that people can carry out to minimise flood damage to their properties. These include moving valuable items to higher places, having sandbags ready and even raising the level of the house. When a flood is imminent, local residents and businesses can undertake preparations like sandbagging their properties, collecting valuable portable items and storing valuable items in safe places if they cannot take them.

For assessing community responses to flooding, 3 indicators were chosen:

1. Evacuation intention. In Victoria, emergency services organisations prefer self-evacuation if a flood is imminent or immediately after a personal notice to evacuate is issued (VICSES 2020). Delaying evacuation or refusing to evacuate can result in the need for emergency rescue or possible injury and death (Haynes et al. 2017).

2. Perceived time to evacuate. Most flooding in the Wimmera region is due to riverine flooding and there is generally at least 24 hours of flood warning lead-time to communities. However, in 2 of the locations in this study area (Halls Gap and Natimuk) flash flooding can occur with less than 6 hours of warning lead-time. In these communities, perception of time to evacuate is critical to safe emergency responses.

3. Willingness to drive through floodwaters. Over half of the flood-related deaths in Australia have been caused by people driving through floodwaters (Haynes et al. 2017).

\section{Interventions}

There are several interventions that can be used to influence flood preparedness and response behaviours. In Australia, these interventions are largely part of the flood-risk management process promoted by the Australian Government (Australian Institute for Disaster Resilience 2017) and are usually developed in the mitigation and prevention phase of the disaster management cycle as flood response modification measures.

Based on the 2017 Wimmera Floodplain Management Strategy, 4 preparedness interventions were chosen for the research framework (see Figure 1):

1. Education and engagement. Community flood education and engagement are commonly used to motivate people to prepare for flooding and respond appropriately, including to evacuate if required and not drive through floodwaters (Dufty 2020). VICSES provides flood education and engagement services across the Wimmera region.

2. Risk communication. Risk communication informs people about a potential future harm and the associated dangers so that they might take action to prepare for and mitigate the risk. Risk communication in the Wimmera region is conducted primarily via the Wimmera CMA (Wimmera CMA 2020).

3. Flood insurance. Property owners are encouraged to take up flood insurance as a preparedness action to help manage potential losses resulting from flooding. The Insurance Council of Australia (2016) estimates that flood insurance coverage for households in Australia is over 93 per cent. However, this high level of coverage is a recent phenomenon. Until 2008, residential flood insurance was broadly unavailable in the eastern states of Australia, which are home to most of Australia's population and have the majority of flood risk. Flood insurance is now available throughout Australia, although insurance affordability remains a concern in high-risk flood regions as pricing reflects the high underlying risk.

4. Community development. Community-development activities can help connect people prior to a flood event and establish support for vulnerable people in the advent of a flood. In the Wimmera region, community development is primarily conducted by local councils, each of which is required to have a Vulnerable Persons Register.

Four response interventions were identified for the research framework (Figure 1):

1. Early warning systems. The aim of an early warning system is to provide people with enough time to make themselves safe when a threat is imminent. A secondary aim is the protection of property. It is important that the safety of companion animals and livestock such as sheep, cattle and horses is considered. A lead guiding document for the development of total flood warning systems in Australia was Manual 21 - Flood Warning (Attorney-General's Department 2009) with this guidance now being part of the Flood Emergency Planning for Disaster Resilience Manual (Australian Institute for Disaster Resilience 2020).

2. Crisis communication. Allied with early warning systems is the range of emergency communication methods and language used by emergency managers to warn people about flooding and encourage safe responses.

3. Emergency management. Emergency services organisations provide services to communities to help keep them safe during a flood. In Victoria, central to flood emergency management arrangements and coordination are municipal flood emergency plans, which are prepared in collaboration by local councils, emergency managers and catchment management authorities.

4. Community support. In many cases, the first responders in a flood emergency are community members, not emergency services agencies. Safe flood responses are therefore contingent on the level and type of community support, including that from community groups and networks. 


\section{Social research survey}

Figure 2 shows that not all the potential inter-relationships in the research framework were tested through this social research project. The social research focused on the relationships between the contributing factors and the preparedness and response indicators, rather than the interventions. This was due to the research interests of the Wimmera CMA regarding the effectiveness of its strategy and the complexity of all possible inter-relationships.

Approximately 800 at-risk households were surveyed across the 6 Wimmera communities. A response rate of 21 per cent was achieved providing a sample with a good level of statistical confidence across the 5 categories of flood risk used in the Wimmera region.

The social research identified numerous issues for the implementation of the strategy, especially relating to the contributing factors. Many residents were unaware of their flood risk including those living in high-flood-risk areas. Eighty per cent of respondents who perceived a high-flood risk indicated that they would not evacuate before a flood. This demonstrates the lack of effect of risk perception on warning response behaviours. Respondents who had companion animals were particularly unwilling to evacuate.

This research found a general 'optimism bias', being that people underestimate flood risk compared with actual flood risk. This was evident even for those respondents who had experienced previous floods. Respondents who had experienced previous floods displayed a 'prison of experience' where their behaviours during past flood events confine their future preparedness and response actions.

The survey responses indicated that almost all respondents did not have a written emergency plan as recommended by emergency services organisations.

In terms of coping appraisal, 19 per cent of respondents indicated they would need assistance in a future flood although only 3 per cent rated their ability to cope as 'not good'.

A positive for the region was the high levels of social capital shown. Eighty per cent of respondents indicated that they would be willing to help others and there were high levels of trust including in emergency services agencies and their local

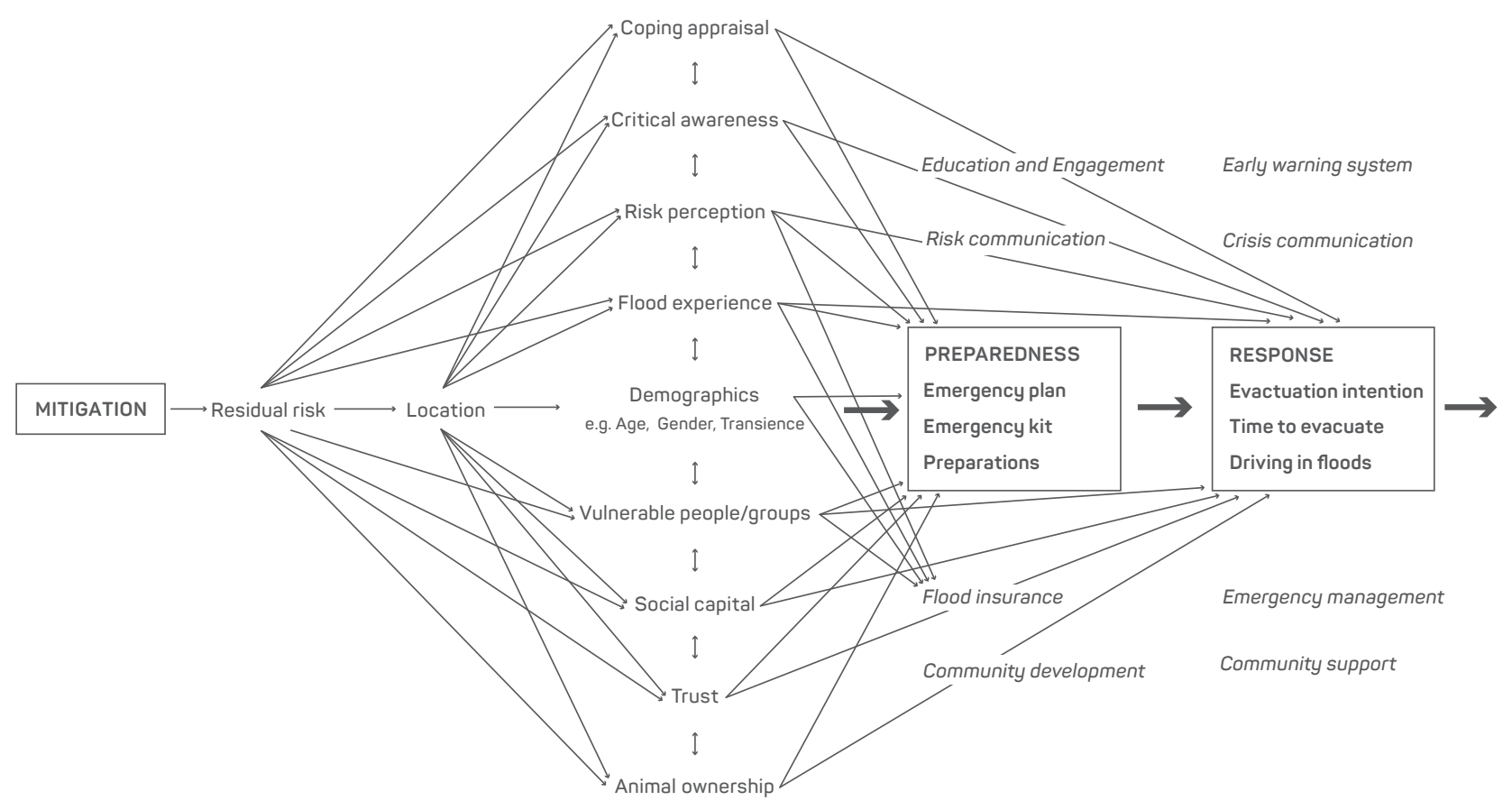

Figure 2: Use of the research framework in the Wimmera region social research project. 
volunteers. There were strong age and gender variances evident including that older males might drive through floodwaters of over $20 \mathrm{~cm}$ in depth. There were also spatial differences in the relationships between the contributing factors and indicators. For example, residents in the smaller villages were more reticent to evacuate but had greater critical awareness of flooding.

Risk perception and previous flood experience were relatively weak contributors to the uptake of flood insurance, which was the only intervention directly tested. Although almost all respondents were aware of flood insurance products, only 59 per cent had flood insurance policies and only 71 per cent had policies in high-risk areas.

As a result of the social research, several interventions relating to community development, flood education and engagement, and emergency management planning were recommended. These were aimed at influencing the contributing factors and preparedness and response indicators identified in the research framework.

\section{Discussion}

The research framework provided an intriguing insight into the psychological and sociological complexities and inter-relationships in which the 2017 Wimmera Floodplain Management Strategy is bedded. It is the intention of the Wimmera CMA to conduct follow-up social research to see if recommended interventions have influenced preparedness and response levels and their contributing factors. Obviously, a major flood in the Wimmera region would strongly influence community flood behaviour and this flood event should be monitored using the research framework.

The research framework has 3 limitations based on the Wimmera social research. Firstly, at this stage, it does not weigh the contributing factors against each other but deals with them with the same level of importance. Secondly, the framework does not accommodate multiple causal factors where several factors may combine rather than one and have a cumulative effect. Lastly, there may be other important components of the research framework that have not been identified. Ongoing research is required to identify and include these components if warranted.

The research framework, built on the nexus of contributing factors and preparedness and response levels and interventions, has universal appeal in understanding and improving community disaster preparedness and response at the community, local, regional and national levels. The framework can be adapted to other hazards (bushfires, pandemics, heatwaves, tsunamis) and compounding hazard events (e.g. tropical cyclones where there is initial wind and storm surge followed by flooding). It can also be reconstructed for other parts of the disaster management cycle (mitigation, recovery) and to assess overall community disaster resilience.

\section{Conclusion}

A research framework was developed to help understand and improve community flood preparedness and response across the Wimmera region of Victoria. The framework was used as a basis for a social research project in the region, which found low preparedness levels, potential reasons for these levels and possible ways to increase the levels. It identified aspects of community response that require attention including unwillingness to evacuate and willingness to drive through floodwaters. The high levels of social capital in the region auger well for community support mechanisms in future flood events.

\section{Acknowledgment}

The Wimmera Catchment Management Authority is acknowledged for the opportunity to conduct this research and special thanks to Mr Paul Fennell, Floodplain Management Team Leader, for his input.

\section{References}

Aldrich DP 2012, Building resilience: social capital in post-disaster recovery, University of Chicago Press, Chicago.

Attorney-General's Department 2009, Flood Warning, Manual 21, Australian Emergency Manuals Series, Commonwealth of Australia.

Australian Institute for Disaster Resilience 2017, Handbook 7-Managing the floodplain: A Guide to Best Practice in Flood Risk Management in Australia. At: https://knowledge.aidr.org.au/ resources/handbook-managing-the-floodplain/.

Australian Institute for Disaster Resilience 2020, Flood Emergency Planning for Disaster Resilience Manual. At: https://knowledge.aidr. org.au/resources/handbook-flood-planning/.

Bankoff G, Frerks G \& Hilhorst D 2004, Mapping vulnerability: disasters, development, and people, Routledge, London and Sterling VA.

Becker JS, Paton D, Johnston DM, Ronan KR \& McClure J 2017, The role of prior experience in informing and motivating earthquake preparedness, International Journal of Disaster Risk Reduction, vol. 22, pp.179-193.

Blaikie P, Cannon T, Davis I \& Wisner B 1994, At risk: Natural hazards, people's vulnerability, and disasters, Routledge, London.

Bubeck P, Botzen WJW \& Aerts J CJH 2012, A Review of Risk Perceptions and Other Factors that Influence Flood Mitigation, Behavior Risk Analysis, vol. 32, no. 9, pp.1481-1485.

Cain A 1985, Pets as family members, in: Pets and the Family (ed. M.Sussman), Haworth Press, New York.

Cope S, Frewer LJ, Houghton J, Rowe G, Fischer RH \& de Jonge $\mathrm{J} 2010$, Consumer perceptions of best practice in flood risk communication and management: Implications for risk analysis policy, Flood Policy, vol. 35, no. 4, pp.349-357. 
Dufty, N 2020, Disaster Education, Communication and Engagement, Wiley, Hoboken, USA.

Grothmann T \& Reusswig F 2006, People at risk of flooding: Why some residents take precautionary action while others do not, Natural Hazards, vol. 38, pp.101-120.

Haynes K, Coates L, van den Honert R, Gissing A, Bird D, de Oliveira F Dimer, D'Arcy R, Smith C \& Radford D 2017, Exploring the circumstances surrounding flood fatalities in Australia-1900-2015 and the implications for policy and practice, Environmental Science \& Policy, vol. 76, pp.165-176.

Healthcare Ready 2020, Annual Preparedness Poll - Key Findings. At: https://healthcareready.org/community-resilience/.

Insurance Council of Australia 2016, Local Government and Insurance - Flood Insurance Pricing. At: www.floods.org.au/ client_images/1787680.pdf.

Karanci AN, Aksit B \& Dirik G 2005, Impact of a community awareness training program in Turkey, Does it influence hazardrelated cognitions and preparedness behaviors, Social Behavior and Personality, vol. 33, no. 3, pp.243-58.

Lindell MK \& Perry RW 2004, Communicating environmental risk in multiethnic communities, Sage, Thousand Oaks.

Mclvor D, Paton D \& Johnston D 2009, Modelling Community Preparation for Natural Hazards: Understanding Hazard Cognitions, Journal of Pacific Rim Psychology, vol. 3, no. 2, pp.39-46.

Miceli R, Sotigiu I \& Settanni M 2008, Disaster preparedness and perception of flood risk: a study in an alpine valley in Italy, Journal of Environmental Psychology, vol. 28, pp.164-173.

National Health and Medical Research Council 2015, National Statement on Ethical Conduct in Human Research, Commonwealth of Australia.

New Zealand Ministry of Civil Defence \& Emergency Management 2013, Get Ready Get Thru Campaign Monitoring Research, July 2013.

Paton D, McClure J \& Burgelt PT 2006, Disaster resilience: building capacity to co-exist with natural hazards and their consequences, in: Disaster Resilience: An Integrated Approach. (eds D. Paton \& D. Johnston), Charles C Thomas Publishers Ltd, Springfield, USA.

Putnam R 1995, Bowling Alone: The Collapse and Revival of American Community, Journal of Democracy, vol. 6, pp.65-78.

Rogers RW 1983, Cognitive and Physiological Processes in Fear Appeals and Attitude Change: A Revised Theory of Protection Motivation, In: Social Psychophysiology: A Sourcebook, (eds J. Cacioppo \& R Petty), Guilford, London.

Scolobig A, De Marchi B \& Borga M 2012, The missing link between flood risk awareness and preparedness: findings from case studies in an Alpine Region, Natural Hazards, vol. 63, pp.499-520.

Terpstra T, Lindell M \& Gutteling J 2009, Does communicating (flood) risk affect (flood) risk perceptions? Results of a quasiexperimental study, Risk Analysis, vol. 29, pp.1141-1155.
Thompson K 2013, Save me, save my dog. Increasing natural disaster preparedness and survival by addressing human-animal relationships, Australian Journal of Communication, vol. 40, no. 1 , pp.123-136.

Thompson K 2018, Facing disasters together: How keeping animals safe benefits humans before, during and after natural disasters, OIE Revue scientifique et technique - office international des epizoottes (special issue on The Contribution of Animals to Human Welfare), vol. 37, no. 1, pp.223-230.

van der Veen A, Dopheide E, Parker D, Tapsell S, Handmer J, Gregg C, Bonadonna C \& Ferrara F 2009, State-of-art on vulnerability of socio-economic systems, Del. 1.1.3 of the ENSURE EC FP7 Project: Methodologies to assess vulnerability of structural, territorial and economic systems. EC, Brussels.

VICSES 2020, Emergency Toolkit: A Guide to Staying Safe, Victorian Government. At: www.ses.vic.gov.au/ documents/112015/135368/Emergency+Toolkit-pdf.

Wimmera CMA 2017, Wimmera Floodplain Management Strategy. At: https://wcma.vic.gov.au/permitsplanningfloodadvice/ FloodplainManagement.

Wimmera CMA 2020, Flood Investigations and Flood Extent Maps. At: https://wcma.vic.gov.au/permitsplanningfloodadvice/ FloodInvestigations.

\section{About the author}

Neil Dufty is a principal at Molino Stewart Pty Ltd, a natural hazards and environment consultancy based in Parramatta, NSW. 